\title{
Editorial
}

\section{Structure determines function}

\author{
Mark J. Heulitt* \\ Section of Critical Care Medicine, Department of Pediatrics, Physiology and Biophysics, College of Medicine, \\ University of Arkansas for Medical Sciences, Little Rock, AR, USA
}

Received 16 January 2013

Revised 4 May 2013

Accepted 16 January 2013

In this special issue of the Journal of Pediatric Intensive Care, we have compiled a series of articles relating to mechanical ventilation. We have chosen to select articles that do not address the usual reviews on mechanical ventilation but rather topics that our readers may find unique and interesting.

The title of my editorial, "Structure determines function", relates to that first lecture in physiology when it was discussed that changes in the shape of a protein, cell or organ will usually result in a change of function of that structure. This is never so true as in a discussion of the physiology of positive pressure mechanical ventilation in pediatric patients. Over the past 20 years, there has been a growing body of literature that served as the basis of a "protective lung strategy" in patients with acute lung injury and acute respiratory distress syndrome $[1,2]$. I published the first review on this topic in pediatric patients in Respiratory Care in 1995 [3,4]. Since then, pediatric intensivists have modified their practice in an attempt to limit iatrogenic lung injury. These strategies, though still debated, usually include a low tidal volume strategy, limited levels of plateau pressure and inspired oxygen with adequate level of positive end expiratory pressure. The basis of the iatrogenic lung injury caused by positive pressure mechanical ventilation

*Address for correspondence: Mark J. Heulitt, Physiology and Biophysics, College of Medicine, University of Arkansas for Medical Sciences, Applied Respiratory Physiology Laboratory Arkansas Children's Hospital Research Institute, Little Rock, AR 722023591, USA. Tel.: +1 501364 1858; Fax: +1 501364 3188; E-mail: heulittmarkj@uams.edu. is a distortion of normal lung architecture (change in structure) with a subsequent change in pulmonary function of gas exchange (change in function). Therefore, all strategies are based in a desire to preserve the normal lung structure, thus function. Adjusting mechanical ventilator strategies as describe above can minimize ventilator induced lung injury and thus decrease mortality [1,2]. Recent reviews have demonstrated reduced mortality rates of $18-35 \%$ in pediatric patients $[5,6]$.

The exact lower limit of the amount of tidal volume that causes structural damage, especially in pediatric patients, is still not known. We know the strategies of the 1980's and early 1990's of tidal volumes in excess of $10 \mathrm{~mL}$ per $\mathrm{kg}$ are deleterious, but the ideal tidal volume in children is still unknown. Due to the lack of this knowledge, strategies have developed to limit the tidal volume ( $8 \mathrm{~mL}$ per $\mathrm{kg}$ or less) along with inspired oxygen and plateau pressure. Further complicating this discussion is the inexact nature of our ability to accurately measure tidal volume in mechanically ventilated pediatric patients. I must remind the reader that we never measure tidal volume during mechanical ventilation, but measure flow and then integrate the flow changes to determine volume. Of course, this technique will not be accurate if not all flow is measured by the pneumotachograph (flow measuring device) such as when the flow is retained in the ventilator circuit (loss due to compression volume), or if there is an airway leak. It has been proposed that due to the above difficulties that in small pediatric patients, accurate tidal volume can only be guaranteed if tidal volume 
is measured by a sensor placed at the patient's endotracheal tube [7]. Subsequent studies by myself and my colleagues have demonstrated that tidal volumes can be measured without an airway sensor; however, there is an associated bias with this technique and all volume must be considered, not just what is associated with the ventilator's circuit compliance loss to ensure these volumes are accurate [8,9]. In this issue, we have presented two articles examining the accuracy of tidal volume measurement with airway sensors. Our goal was to examine the different engineering solutions offered by these devices and determine their accuracy in extremely small tidal volumes such as those utilized preterm neonates. Our results show that the addition of an airway sensor does not guarantee volume will be measured accurately and that bias does exist. Also, there are considerable differences between the three types of airway sensors utilized in regards to both bias and precision of the volume measured. Finally, we included an article that looked at the accuracy of volume measurement when helium is added to the ventilator circuit in patients with increased airway resistance. Recently, a manufacturer has introduced a system that internally adjusts for the effects of helium-oxygen mixture on the accuracy of volume measurement by the ventilator's pneumotachograph. Unfortunately, our results demonstrate that volume measurements continue to be inaccurate even with systems that have internal adjustments. We recommend that clinicians should be vigilant in monitoring delivered tidal volumes using a commercially available ventilator equipped with an internal helium-oxygen blending system.

In addition to the original scientific studies described above, we have included three unique review articles again addressing unique problems encountered when pediatric patients are supported with positive pressure mechanical ventilation. The first review is an excellent discussion of the issue of triggering and spontaneous breathing during mechanical ventilation. This is a problem often discussed on rounds in the intensive care unit (ICU); however, the scope of the problem is just becoming evident to clinicians. Issues relating to triggering and asynchrony are important in mechanical ventilation in pediatric patients $[10,11]$. In a recent animal study examining this issue in my laboratory, we documented a significant incidence of asynchrony in a recovering animal model and considerable variation associated with different modes of ventilation [12]. Similar findings were found in pediatric patients recovering from bronchiolitis [13]. This issue is important in the scope of our previous discussion of lung protection since it has been proposed that spontaneous breathing may be protective in its own right [14]. Clinicians need to understand the limitations of different modes of mechanical ventilation and factors that may lead to difficulties in triggering and asynchrony and adjust accordingly in their patients.

The second review examines the affects of sleep in the ICU and the effects of mechanical ventilation on sleep. This is another topic that is not studied in pediatric patients, but is clinically important in the care of mechanically ventilated patients. Although all of sleep's purposes are unknown, sleep deprivation has serious consequences. It is well known that the ICU environment is not favorable for sleep. Mechanical ventilation is an intervention that is vital in the support of critically ill patients during their treatment course. However, activities related to ventilation contribute to sleep disturbance including suctioning, pain of endotracheal tube, noise of alarms, over ventilation, and patient-ventilator asynchrony. It has been found in adults that apneas and asynchrony lead to increased arousals, awakenings, and decreased sleep efficiency [15]. The complex nature of the issues of causes of ventilator synchrony and sleep quality requires a greater understanding of this relationship in pediatric patients. Perhaps the most important question posed by this outstanding review is whether improvement of sleep in the ICU is a goal for physicians.

The final review is a discussion of a unique use of increased respiratory frequency to create a lung protective strategy. The strategy is called Mid-Frequency ventilation (MFV) which is a mode of mechanical ventilation where pressure controlled breaths are delivered at higher than usual respiratory rates with a conventional ventilator. The use of higher than normal frequencies has been used in clinical practice for the last 30 years. However, MFV is based in the mathematical modeling of a pressure control breath; were as ventilator frequency increases, at a constant I:E ratio, alveolar ventilation demonstrates a peak (maximized). This peak is typically found at higher than usual respiratory rates (optimal frequency) and lower tidal volume. The clinical consequence is that for a given alveolar ventilation target, MFV provides optimal inspiratory pressure and respiratory frequency with the least tidal volume. Even though this approach is still theoretical, however it still offers an alternative to the traditional approach in neonatal and pediatric patients who fail a conventional low tidal volume protective lung strategy who are usually transitioned to either high frequency ventilation (HFV), which delivers small tidal volume 
at fast respiratory rates or more invasive and expensive support such as extracorporeal membrane oxygenation. Due to the specialized ventilator required to administer $\mathrm{HFV}$, the ability to monitor potential lung overdistension is limited, as well as the ability to transport within the institution for diagnostic services or to other institutions for specialized care. High frequency ventilators are an expensive limited resource, and availability would be severely limited in epidemics causing respiratory failure. The ability to use a conventional ventilator to perform lung recruitment without causing ventilator induced lung injury in patients who fail a traditional lung protective strategy would expand availability of resources and improve versatility of care in place of HFV.

In summary, concerns discussed in this issue do not require state of the art equipment, but a clinician who identifies these issues as important and prioritizes their decisions to protect the lung and create the most ideal environment for their patient.

\section{References}

[1] Gajic O, Dara SI, Mendez JL, Adesanya AO, Festic E, Caples SM, et al. Ventilator-associated lung injury in patients without acute lung injury at the onset of mechanical ventilation. Crit Care Med 2004;32(9):1817-24.

[2] Dreyfuss D, Saumon G. Ventilator-induced lung injury: lessons from experimental studies. Am J Respir Crit Care Med 1998;157(1):294-323.

[3] Heulitt MJ, Anders M, Benham D. Acute respiratory distress syndrome in pediatric patients: redirecting therapy to reduce iatrogenic lung injury. Respir Care 1995;40(1):74-85.

[4] Heulitt MJ, Desmond B. Lung protective strategies in pediatric patients with ARDS. Respir Care 1998;43(11):952-60.

[5] Flori HR, Glidden DV, Rutherford GW, Matthay MA. Pediatric acute lung injury: Prospective evaluation of risk factors associated with mortality. Am J Respir Crit Care Med 2005; 171(9):995-1001.

[6] Erickson S, Schibler A, Numa A, Nuthall G, Yung M, Pascoe E, et al. Acute lung injury in pediatric intensive care in Australia and New Zealand: A prospective, multicenter, observational study. Pediatr Crit Care Med 2007;8(4):317-23.

[7] Cannon ML, Cornell J, Tripp-Hamel DS, Gentile MA, Hubble CL, Meliones JN, et al. Tidal volumes for ventilated infants should be determined with a pneumotachometer placed at the endotracheal tube. Am J Respir Crit Care Med 2000;162(6): 2109-12.

[8] Heulitt MJ, Holt SJ, Thurman TL, Hall RA, Jo CH, Simpson P. Reliability of measured tidal volume in mechanically ventilated young pigs with normal lungs. Intensive Care Med 2005;31(9): 1255-61.

[9] Heulitt MJ, Thurman TL, Holt SJ, Jo CH, Simpson PM. Reliability of displayed tidal volume in infants and children during dual-controlled ventilation. Pediatr Crit Care Med 2009;10(6): 661-7.

[10] Heulitt MJ. Update in neonatal and pediatric mechanical ventilation: Patient ventilator interactions. Can J Resp Ther 2011;47(2):29-38.

[11] Rimensberger PC, Heulitt MJ, Meliones J, Pons M, Bronicki RA. Mechanical ventilation in the pediatric cardiac intensive care unit: The essentials. World J Pediatr Congenital Heart Surg 2011;2(4):609-19.

[12] Heulitt MJ, Clement KC, Holt SJ, Thurman TL, Jo CH. Neurally triggered breaths have reduced response time, work of breathing, and asynchrony compared with pneumatically triggered breaths in a recovering animal model of lung injury. Pediatr Crit Care Med 2012;13(3):e195-203.

[13] Clement KC, Thurman TL, Holt SJ, Heulitt MJ. Neurally triggered breaths reduce trigger delay and improve ventilator response times in ventilated infants with bronchiolitis. Intensive Care Med 2011;37(11):1826-32.

[14] Vimlati L, Kawati R, Hedenstierna G, Larsson A, LichtwarckAschoff M. Spontaneous breathing improves shunt fraction and oxygenation in comparison with controlled ventilation at a similar amount of lung collapse. Anesth Analg 2011;113(5): 1089-95.

[15] Parthasarthy S, Tobin MJ. Effect of ventilator mode on sleep quality in critically ill patients. Am J Respir Crit Care Med 2002;166(11):1423-9. 